\title{
Transcriptome and proteome analysis of tyrosine kinase inhibitor treated canine mast cell tumour cells identifies potentially kit signaling-dependent genes
}

\author{
Robert Klopfleisch ${ }^{1 *}$, Anja Meyer ${ }^{1}$, Patricia Schlieben ${ }^{1}$, Angelika Bondzio², Chris Weise $^{3}$, Dido Lenze ${ }^{4}$,
} Michael Hummel ${ }^{4}$, Ralf Einspanier ${ }^{2}$ and Achim D Gruber ${ }^{1}$

\begin{abstract}
Background: Canine mast cell tumour proliferation depends to a large extent on the activity of KIT, a tyrosine kinase receptor. Inhibitors of the KIT tyrosine kinase have recently been introduced and successfully applied as a therapeutic agent for this tumour type. However, little is known on the downstream target genes of this signaling pathway and molecular changes after inhibition.

Results: Transcriptome analysis of the canine mast cell tumour cell line C2 treated for up to 72 hours with the tyrosine kinase inhibitor masitinib identified significant changes in the expression levels of approximately 3500 genes or $16 \%$ of the canine genome. Approximately $40 \%$ of these genes had increased mRNA expression levels including genes associated with the pro-proliferative pathways of B- and T-cell receptors, chemokine receptors, steroid hormone receptors and EPO-, RAS and MAP kinase signaling. Proteome analysis of C2 cells treated for 72 hours identified 24 proteins with changed expression levels, most of which being involved in gene transcription, e.g. EIA3, EIA4, TARDBP, protein folding, e.g. HSP90, UCHL3, PDIA3 and protection from oxidative stress, GSTT3, SELENBP1.

Conclusions: Transcriptome and proteome analysis of neoplastic canine mast cells treated with masitinib confirmed the strong important and complex role of KIT in these cells. Approximately $16 \%$ of the total canine genome and thus the majority of the active genes were significantly transcriptionally regulated. Most of these changes were associated with reduced proliferation and metabolism of treated cells. Interestingly, several proproliferative pathways were up-regulated, which may represent attempts of masitinib treated cells to activate alternative pro-proliferative pathways. These pathways may contain hypothetical targets for a combination therapy with masitinib to further improve its therapeutic effect.
\end{abstract}

Keywords: KIT, Mast cell tumour, Dog, 2D-DIGE, MALDI, Mastocytosis, Tyrosine kinase inhibition

\section{Background}

Canine mast cell tumours (MCT) are currently treated with one or a combination of four different therapeutic approaches: surgical, radiation, classical chemotherapy and the recently introduced tyrosine kinase inhibitors (TKI) [1-3]. The latter mainly act by inhibiting the stem

\footnotetext{
* Correspondence: robert.klopfleisch@fu-berlin.de

'Department of Veterinary Pathology, Freie Universität Berlin,

Robert-von-Ostertag-Strasse 15, Berlin 14163, Germany

Full list of author information is available at the end of the article
}

cell factor receptor KIT, the activation of which is one of the most important proliferation stimuli of normal and neoplastic mast cells $[1,4]$.

KIT is constitutively expressed on normal and neoplastic canine mast cells [5]. Due to its central role in mast cell biology and carcinogenesis a special research focus has been placed on the understanding of KIT for canine MCT development, malignant progression and treatment in recent years. Several KIT mutations have been identified, which are associated with aberrant KIT

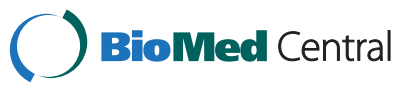


signalling and thus seems to be a major carcinogenic factor for a subset of canine mast cells $[1,6]$. For instance, tandem duplications in the juxtamembrane subunit of KIT have been identified in up to $12 \%$ of all canine MCT and $40 \%$ of malignant grade III MCT [6-8]. This mutation results in a constitutively activated KIT tyrosine kinase and leads to increased malignant behaviour in most affected tumours [1]. As a consequence TKI have been introduced for MCT treatment [9-12]. The action of TKI is not restricted to the tyrosine kinase subunit of KIT but other tyrosine kinases are also inhibited [12,13]. Nevertheless, the activity of non-KIT tyrosine kinases appear much lesser relevant for canine mast cell proliferation and the principle of TKI action in canine MCT is thus thought to mostly rely on KIT inhibition $[1,13]$.

Masitinib is a tyrosine kinase inhibitor that selectively targets KIT, the platelet-derived growth factor receptors $\alpha$ and $\beta$ (PDGFR- $\alpha / \beta)$ and the Src family kinases [13]. Masitinib has been successfully used in the treatment of canine MCT $[9,14]$. In addition to its direct effects on MCT by KIT inhibition, in vitro and in vivo, pilot studies indicate that masitinib also has a potential for chemosensitisation to classic chemotherapeutic agents including gemcitabine, vinblastine and doxorubicin [15-17].

Despite these ongoing efforts in KIT research in veterinary oncology, little is known on the downstream signal transduction pathways, target genes and cell functions associated with KIT activity. The present explorative study therefore aimed at identifying the transcriptional and translational changes after treatment of neoplastic canine mast cells with the TKI masitinib using transcriptome and proteome analysis.

\section{Results \\ Cell proliferation, metabolism and death after masitinib treatment}

Treatment of C2 cells with $100 \mathrm{nM}$ masitinib induced a complete growth arrest with stable cell counts during 72 hours of treatment. In contrast, cell numbers in untreated C2 cells constantly increased during the experiment with an almost 3-fold rise of cell counts after 72 hours.

A WST-1 assay was performed to assess mitochondrial function before exposure, and after 24, 48 and 72 hours of masitinib exposure (Figure 1). There was an approximately $60 \%$ reduction in WST-1 conversion of masitinib treated cells at all indicated time points when compared to the initial activity of the untreated cells. A starting point analysis was chosen to reduce the influence of variable cell concentrations of treated and untreated cell cultures and the different metabolic activity during the different growth curve phases of untreated cells.

LDH-leakage assay identified a significant increase of $11.4 \%$ after 72 hours but no changes after 24 and 48 hours,

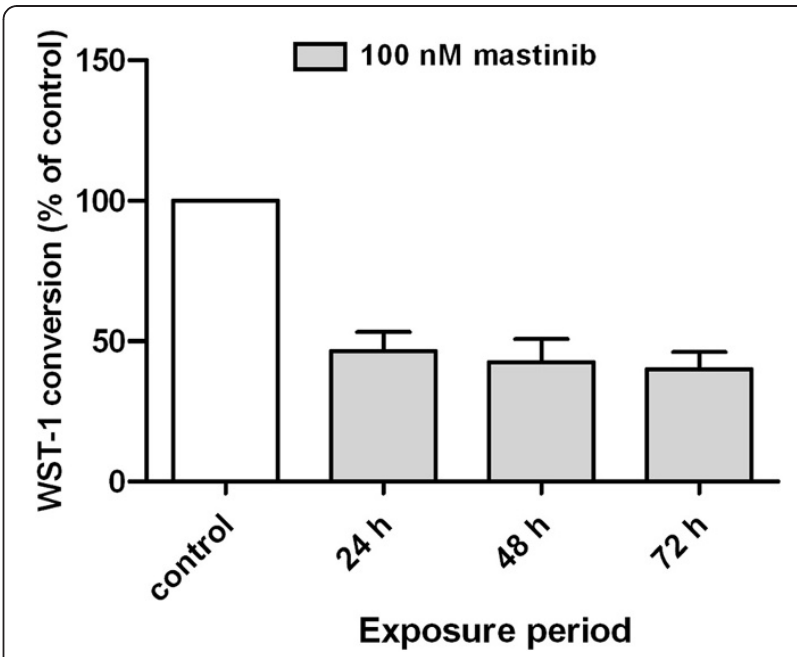

Figure 1 Effect of masitinib on WST-1 conversion. Masitinib treatment (100 $\mathrm{nM}$ ) reduced the metabolic activity of C2 cells by $54 \%$ after 24 hours of treatment. The metabolic activity further decreased up to $40 \%$ at 72 hours. Data shown represent the means +/-SD of five independent experiments with C2 cells, each performed in three to five wells.

indicating only a reduced level of cell death and cytotoxicity at the masitinib concentration used (Figure 2).

\section{Changes in the transcriptome after masitinib treatment}

Treatment of C2 cells with masitinib (100nM) induced a massive change in their global gene expression pattern. A total of 2,116, 3,087 and 3,502 genes had significant changes in their expression levels of $>1.5$-fold after 12 , 24 and 72 h, respectively (Figure 3, Additional file 1). Approximately $59 \%$ of these genes had decreased expression levels while the rest had increased expression. Approximately one third of these genes code for nuclear proteins while $18-26 \%$ of the gene products are expressed in the cytoplasm and in cell organelles (Figure 4).

Most nuclear factors were involved in mitosis and DNA replication (Figure 5), which were mostly downregulated after masitinib treatment. In addition, genes associated with stress response, glycolysis and the citrate cycle were significantly down-regulated (Figure 5).

An up-regulation of mRNA expression levels was mostly observed for genes associated with Golgi apparatus, endoplasmic reticulum and lysosomes and genes associated with apoptosis and proteolysis (Figure 6). Of note, a set of pro-apoptotic genes were significantly enriched in both, up-regulated and down-regulated, groups of genes.

Pathway analysis identified a significant down-regulation of gene expression levels associated with p53, steroid receptor and GTPase-associated signal transduction pathways. In contrast, there was a time dependent increase in the number of up-regulated genes associated with signal transduction pathways during masitinib treatment. After 12 hours 


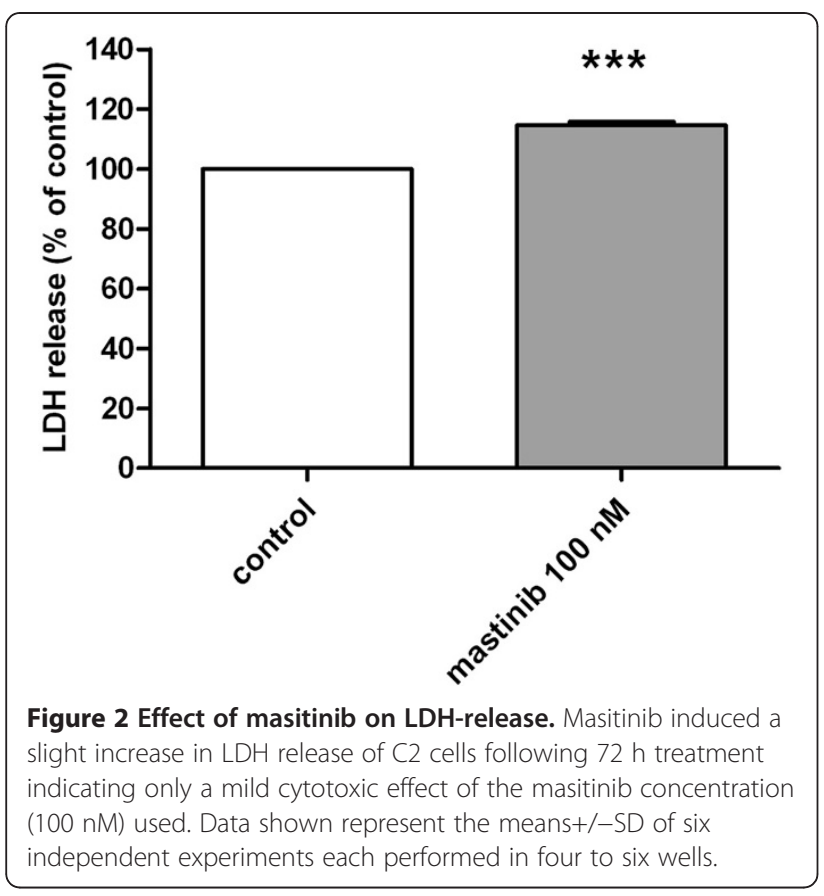

of masitinib treatment there was a significant up-regulation of genes associated with three signal transduction pathways, i.e. T-cell receptor, insulin receptor and steroid hormone receptor. At 24 hours genes associated with five additional pathways were up-regulated, i.e. thyroid receptor, vitamin D receptor, Ras cascade, IL10 receptor and IGE receptor. Finally, at 72 hours up-regulation of genes associated with 15 signal transduction pathways were recorded, the aforementioned pathways and the signalling cascades of the B-cell receptor, MAP kinase, EGF receptor, focal adhesion, CXCR4 receptor, EPO signalling and PTEN signalling (Figure 7).
A correlation analysis of expression levels with the different timepoints identified 89 genes with a time dependent, continuous up-regulation in gene expression levels during masitinib treatment, including the cyclindependent kinase inhibitor 1A (p21, Cip1), parathyroid hormone $(\mathrm{PTH})$ and platelet/endothelial cell adhesion molecule 1 (PECAM1) (Additional file 2). DAVID analysis identified a significant enrichment of the functional annotations apoptosis, ATM-signalling pathway, RAS protein signal transduction, aging, B-cell proliferation and unfolded protein response in this group of genes. A correlation analysis identified 55 genes that had a time dependent, continuous decrease in expression levels during masitinib treatment, including EIF2 and EIF5. Enriched functional annotations in this gene subset were butyrate and pyruvate metabolism, mitochondrial functions, cell migration, apoptosis and mitosis (Additional file 2).

\section{Changes in the proteome after masitinib treatment}

2D-DIGE and MALDI-TOF analyses of the proteome after 24 and 72 hours of masitinib treatment identified 24 proteins with significant differences in protein expression levels when compared to the proteome before masitinib treatment (Figure $8 \mathrm{~A}$ and $8 \mathrm{~B}$ ). Three proteins, TAR-DNA binding protein (TARDBP, 1.52-fold, $p=0.012$ ), eukaryotic translation initiation factor 3 (EIF3, 1.30-fold, $p=0.014$ ) and the actin related protein 2 (ACTR 2, 1.09-fold, $p=0.0054$ ) were down-regulated after 24 hours of masitinib treatment (Table 1). Only two proteins, annexin A1 (ANXA1, 1.66-fold, $p=0.0087$ ) and the gelsolin-like capping protein (CAPG, 1.66-fold, $p=0.0039$ ) were upregulated after 24 hours of masitinib treatment.

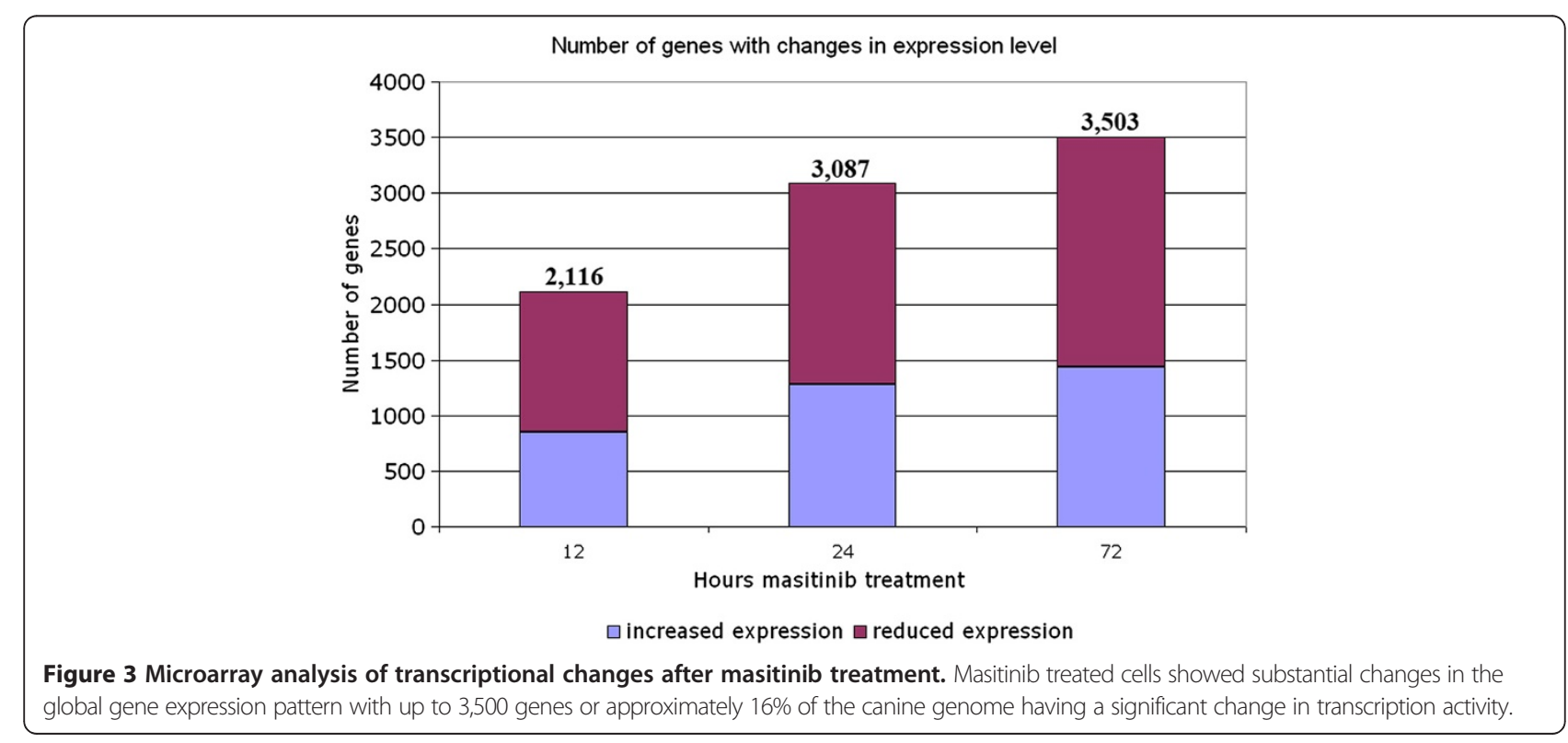


Location of gene products differentially expressed after masitinib treatment

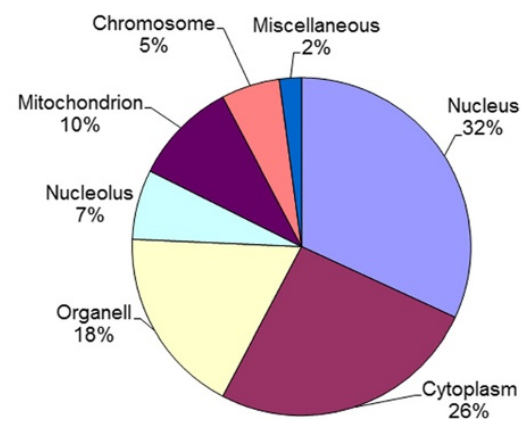

Figure 4 Cellular location of gene products differentially expressed after masitinib treatment.

The effect of masitinib treatment on all five proteins was confirmed by comparing the proteome at 72 hours of treatment with the pre-treatment proteome. All five proteins were identified as significantly regulated at 24 hours and having an even increased expression level after 72 hours treatment (Figure 8B, Table 2). Nineteen additional proteins had significant changes in expression levels after 72 hours treatment (Table 2). Proteins with the highest down-regulation were the eukaryotic translation initiation factor 4a (EIF4A, 1.66-fold, $p=0.005$ ), Tcomplex protein 1 alpha (TCP1A, 1.63-fold, $p=0.019$ ) and the inorganic pyrophosphatase 1 (PPA1, 1.25-fold, $p=0.021$ ). In addition to the two proteins with increased expression levels after 24 hours, 14 up-regulated proteins were identified after 72 hours of masitinib treatment. Of these, iroquois homeobox 6 (IRX6, 1.74-fold, $\mathrm{p}=0.0018$ ), selenium binding protein 1 (SELENBP1, 1.65-fold, $p=0.0011)$, ubiquitin carboxyl-terminal esterase L3 (UCHL3, 1.51-fold, $p=0.027$ ) and annexin A6 (ANXA6, 1.50 -fold, $p=0.031$ ) had the highest up-regulation in protein expression levels.
Comparison with the set of genes identified in the transcriptome analysis identified 15 gene products to be present in the list of mRNA and proteins with significant changes in expression levels. mRNA expressions from 6 of the 8 down-regulated proteins after masitinib treatment were also down-regulated. Furthermore, mRNA from 9 of the 15 proteins up-regulated in C2 treated cells was also present in the transcriptome analysis. However, only five of the transcripts were up-regulated whereas four were down-regulated, in contrast to the situation at the protein level.

\section{Discussion}

The present study aimed at identifying the transcriptional and translational responses of KIT-mutant canine mast cells after treatment with the TKI masitinib. To this end, C2 cells, a cell line with a tandem duplication in the juxtamembrane unit and thus constitutively activated KIT, were treated with masitinib and changes in the global mRNA and protein expression levels were characterised. Due to the strong dependency of neoplastic mast cell proliferation on the constitutively activated KIT it was hypothesized that the observed effects may directly or indirectly be caused by the inhibition of KIT $[1,13]$.

Treatment of $\mathrm{C} 2$ cells with masitinib resulted to a significant change in mRNA expression levels of a substantial number of genes. More than 3,500 genes had upregulated mRNA expression levels after 72 hours of masitinib treatment. This gene number corresponds to approximately $16 \%$ of the suspected 22,000 genes in the canine genome [18]. According to estimations in human cells, approximately 4,000 genes or $16 \%$ of the complete coding genome is active in a given cell on average [19], indicating that almost the complete set of active genes in the $\mathrm{C} 2$ cells responds to masitinib treatment. This, however, is only a very rough estimation since the

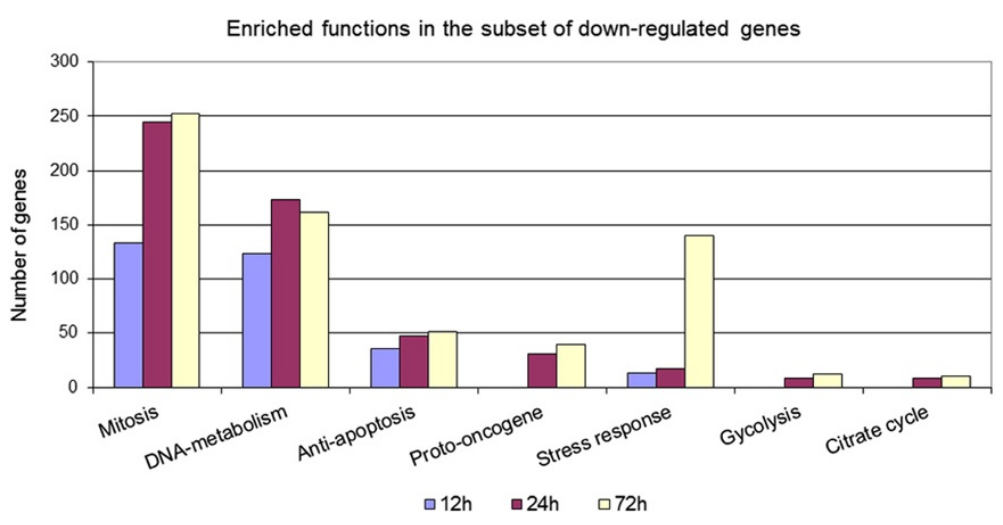

Figure $\mathbf{5}$ Gene functions enriched in the subset of down-regulated genes. Genes associated with functions in cell division, anti-apoptosis, stress response, carbohydrate metabolism were significantly enriched in the subset of down-regulated genes after masitinib treatment. 


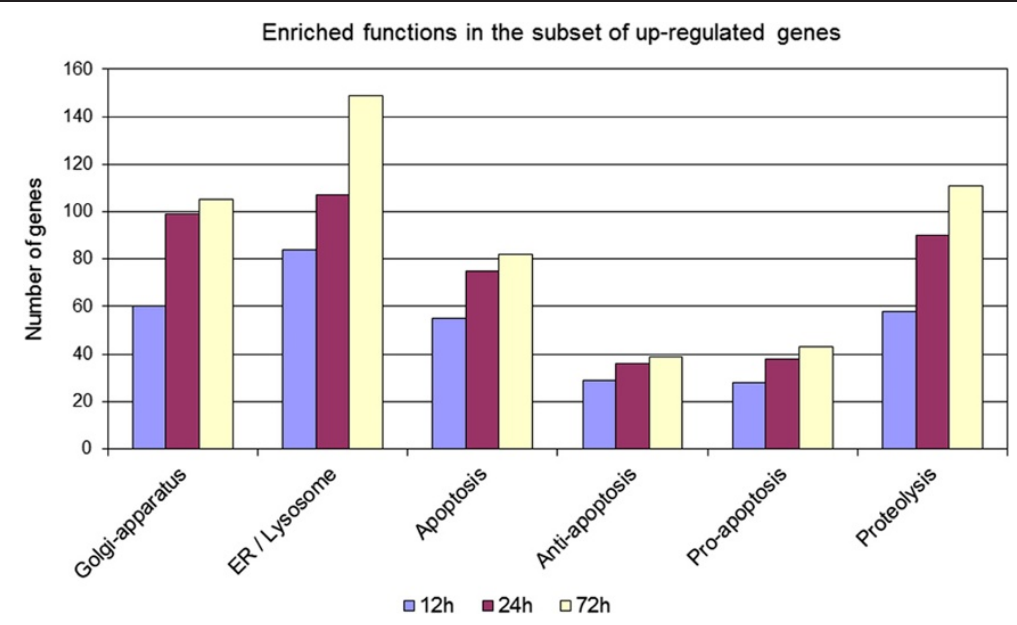

Figure 6 Gene functions enriched in the subset of up-regulated genes. Genes associated with functions in the Golgi-apparatus, the endoplasmic reticulum and apoptosis were significantly enriched in the subset of up-regulated genes after masitinib treatment.

number of active genes may certainly be different in the analysed neoplastic mast cells.

The initial observation of reduced proliferation and metabolism of masitinib treated cells lead to the hypothesis that masitinib treatment and thus KIT inhibition causes a severe shut off of gene activity in treated cells. The results of the transcriptome analysis however indicate that almost half of the regulated genes were transcriptionally up-regulated. Relatively few of these genes had a time dependent up- or down-regulation after masitinib treatment as indicated by the analysis of a potential correlation of the changes in gene expression levels and increasing treatment times.

The active transcriptional response of $\mathrm{C} 2$ cells to masitinib treatment is in accordance with the observation that there was only a mild increase in LDH release and thus cell death in the medium of masitinib treated cells even after 72 hours. $\mathrm{C} 2$ cells therefore seem to actively respond to KIT inhibition with an alternative quantitative and qualitative gene expression pattern to circumvent cell death. For instance, 15 receptor pathways were upregulated after 72 hours of masitinib treatment, most of which have a potential pro-proliferative activity. It can thus be hypothesised that those pathways may contain potential targets for combination therapy.

A subsequent proteome analysis identified 24 proteins with significant changes in protein expression after 72 hours masitinib treatment. $65 \%$ of the proteins also had significant changes in the mRNA expression levels. The total number of proteins is therefore surprisingly low when compared to the large number of transcripts affected. One of the reasons may be a delayed response of the proteome to the changes in the transcriptome and changes in mRNA expression levels may therefore not be reflected after 72 hours [20]. Another point may be the complete metabolic shut off of treated cells which may also severely hamper the protein metabolism of the cells. miRNA as potent regulators of mRNA translation

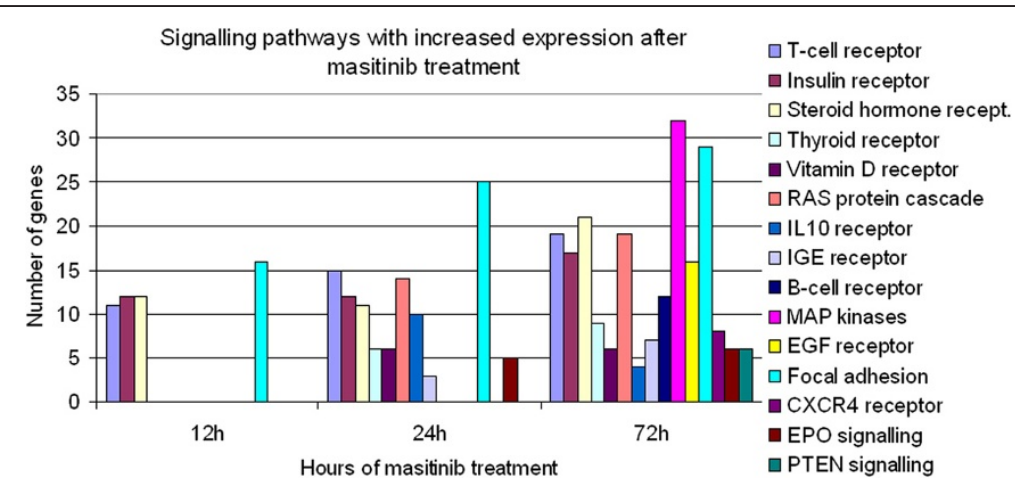

Figure 7 Potentially KIT dependant pathways. Several pro-proliferative pathways have up-regulated mRNA expression levels after masitinib treatment and may thus reflect efforts of treated cells to activate alternative proliferation stimuli and circumvent growth arrest and cell death. 


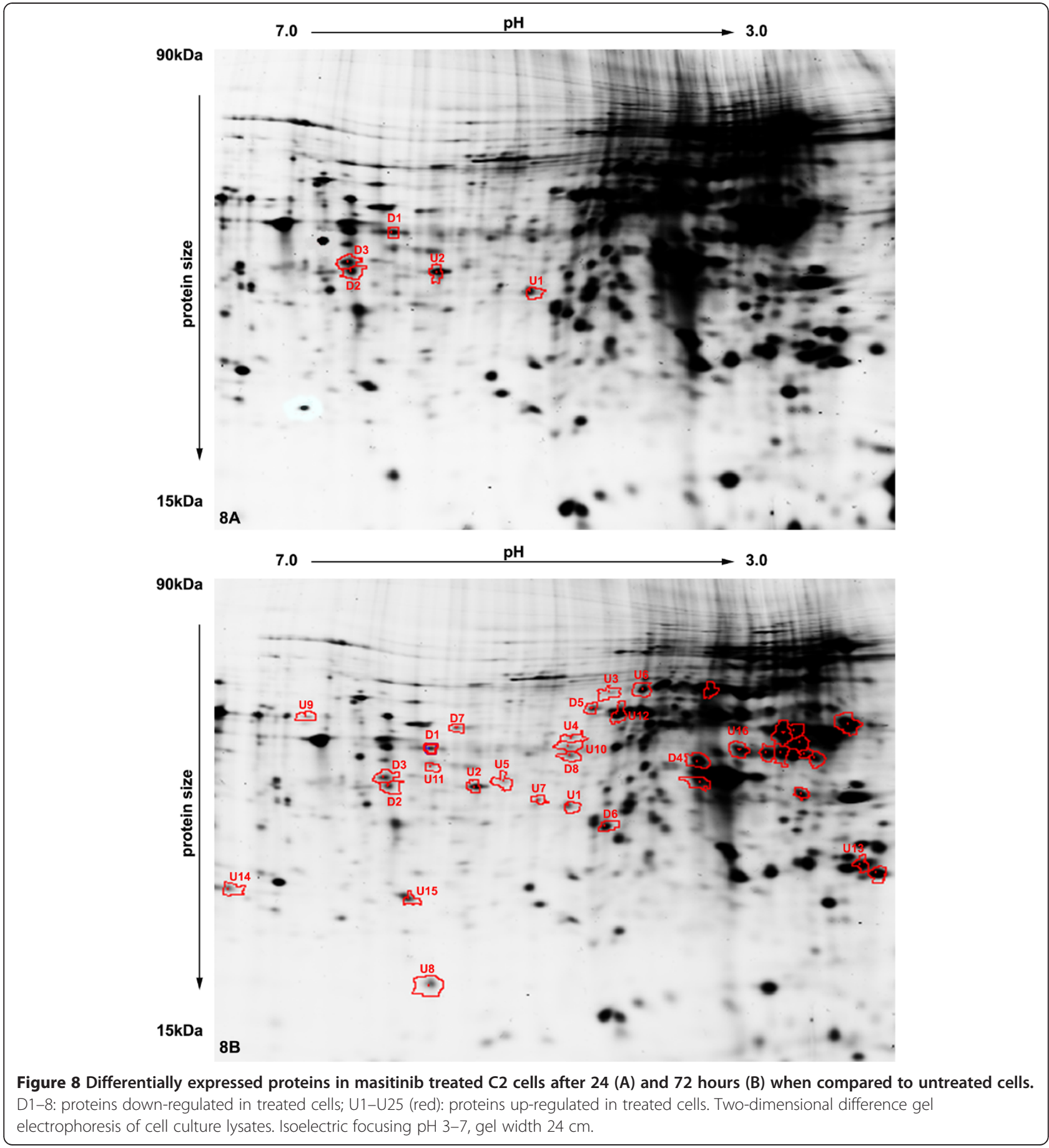

efficiency may also have influenced the differences in mRNA and protein expression levels. On the other hand, two-dimensional difference gel electrophoresis is known to cover only a fraction of the complete proteome while hydrophobic proteins, e.g. membrane proteins and strongly acidic and basic proteins are difficult to separate and visualise by gel electrophoresis. In addition, the differences in the dynamic range of protein and mRNA detection methods also significantly differ and influence the number and intensity of detected mRNA and protein species [21].

\section{Conclusions}

In conclusion, masitinib treatment of neoplastic mast cells leads to a massive change in the global mRNA expression pattern while only few proteins had significant changes in expression levels after three days of treatment. In contrast to our initial hypothesis, a surprisingly high number of 
Table 1 Down- or up-regulated proteins after 24 hours masitinib treatment

\begin{tabular}{|c|c|c|c|c|c|c|c|c|c|}
\hline Spot & Identified protein & AV & p-value & $\begin{array}{c}\text { accession no. } \\
\text { in NCBI }\end{array}$ & $\mathrm{MW}[\mathrm{Da}]^{\S}$ & $\mathrm{pl}^{\S}$ & $\begin{array}{c}\text { MOWSE } \\
\text { score }\end{array}$ & $\begin{array}{l}\text { assigned } \\
\text { peptides }\end{array}$ & $\begin{array}{c}\text { sequ. cov. } \\
{[\%]}\end{array}$ \\
\hline \multicolumn{10}{|c|}{ Down-regulated proteins } \\
\hline 1 & TARDBP & -1.52 & 0.012 & gi|6678271 (Ho) & 45053 & 5.85 & 53 & $1^{*}$ & $4^{*}$ \\
\hline 2 & EIF3 & -1.30 & 0.014 & gi|73974369 (Ca) & 29504 & 7.78 & 92 & 8 & 21 \\
\hline 3 & ACTR2 & -1.09 & 0.0054 & gi|73969816 (Ca) & 36488 & 8.21 & 46 & $1^{*}$ & $4^{*}$ \\
\hline \multicolumn{10}{|c|}{ Up-regulated proteins } \\
\hline 4 & ANXA1 & +1.66 & 0.0087 & gil73946797 (Ca) & 38887 & 5.84 & 91 & 12 & 31 \\
\hline 5 & CAPG & +1.66 & 0.0039 & gil73980918 (Ca) & 39088 & 6.04 & 85 & 6 & 24 \\
\hline
\end{tabular}

\$The listed molecular weights and pl values correspond to the listed accession numbers, which sometimes belong to species other than Canis familiaris (Ca.). *These proteins were identified by unique peptide sequences determined by MALDI-TOF MS/MS experiments.

Abbreviations: EIF3: eukaryotic translation initiation factor 3; ACTR2: actin-related protein 2; ANXA1: annexin A1; MCP: Macrophage capping protein; Ca: Canis familiaris; Ho: Homo sapiens.

Table 2 Down- or up-regulated proteins after 72 hours masitinib treatment

\begin{tabular}{|c|c|c|c|c|c|c|c|c|c|}
\hline Spot. & Identified protein & AV & $t$ test & accession no. in NCBI & $\mathrm{MW}[\mathrm{Da}]^{2}$ & $\mathrm{pl}^{\S}$ & $\begin{array}{c}\text { MOWSE } \\
\text { score }\end{array}$ & $\begin{array}{l}\text { assigned } \\
\text { peptides }\end{array}$ & $\begin{array}{c}\text { sequ. cov. } \\
{[\%]}\end{array}$ \\
\hline \multicolumn{10}{|c|}{ Down-regulated proteins } \\
\hline 1 & TARDBP43 & -2.62 & 0.019 & gi|6678271 (Ho) & 45053 & 5.85 & 53 & $1^{*}$ & $4^{*}$ \\
\hline 6 & ElF4A & -1.66 & 0.005 & gi|73966207 (Ca) & 44692 & 5.40 & 89 & 15 & 41 \\
\hline 7 & TCP1A & -1.63 & 0.019 & gi|73945755 (Ca) & 60943 & 5.71 & 80 & 9 & 17 \\
\hline 2 & EIF3 & -1.33 & 0.012 & gi|73974369 (Ca) & 29504 & 7.78 & 92 & 8 & 21 \\
\hline 8 & PPA1 & -1.25 & 0.021 & gi|73953384 (Ca) & 33372 & 5.80 & 34 & $1^{*}$ & $2^{*}$ \\
\hline 9 & $\mathrm{CCT} 2$ & -1.25 & 0.042 & gi|73968673 (Ca) & 57737 & 6.01 & 80 & 8 & 17 \\
\hline 3 & ACTR2 & -1.12 & 0.019 & gi|73969816 (Ca) & 36488 & 8.21 & 46 & $1^{*}$ & $4^{*}$ \\
\hline 10 & PSMD6 & -1.06 & 0.040 & gi|73981961 (Ca) & 99123 & 9.57 & 72 & 10 & 12 \\
\hline \multicolumn{10}{|c|}{ Up-regulated proteins } \\
\hline 11 & HSP90B1 & +1.18 & 0.048 & gi|50979116 (Ca) & 22925 & 6.23 & 74 & 5 & 24 \\
\hline 11 & GSTT3 & +1.20 & 0.0077 & gi|73995693 (Ca) & 27793 & 6.67 & 98 & 8 & 33 \\
\hline 12 & YWHAZ. & +1.22 & 0.019 & gi|73974186 (Ca) & 26438 & 5.00 & 156 & 17 & 52 \\
\hline 13 & PDIA3 & +1.26 & 0.012 & gi|74000349 (Ca) & 76474 & 8.95 & 161 & 21 & 30 \\
\hline 14 & CORO1A & +1.34 & 0.017 & gi|73958506 (Ca) & 41955 & 7.10 & 52 & $1^{*}$ & $2^{*}$ \\
\hline 15 & ТТС38 & +1.34 & 0.016 & gi|73968897 (Ca) & 52886 & 5.67 & 79 & 6 & 12 \\
\hline 16 & OXCT1 & +1.43 & 0.028 & gi|73954281 (Ca) & 65275 & 7.92 & 90 & 10 & 18 \\
\hline 17 & SEMG1 & +1.45 & 0.017 & gi|134093092 (Go) & 52065 & 8.96 & 83 & 8 & 19 \\
\hline 18 & UROD & +1.45 & 0.016 & gi|73977144 (Ca) & 35096 & 5.50 & 105 & 9 & 29 \\
\hline 19 & ANXA6 & +1.50 & 0.031 & gi|73953627 (Ca) & 76241 & 5.47 & 207 & 23 & 32 \\
\hline 20 & UCHL3 & +1.51 & 0.027 & gi|158749588 (Ra) & 26278 & 5.01 & 74 & 5 & 23 \\
\hline 21 & SELENBP1 & +1.65 & 0.0011 & gi|73981582 (Ca) & 67142 & 7.59 & 89 & 9 & 20 \\
\hline 22 & IRX6 & +1.74 & 0.0018 & gi|121484129(Pa) & 24682 & 8.99 & 74 & 5 & 24 \\
\hline 5 & CAPG & +1.98 & 0.0036 & gi|73980918 (Ca) & 39088 & 6.04 & 85 & 6 & 24 \\
\hline 4 & ANXA1 & +2.58 & 0.007 & gi|73946797 (Ca) & 38887 & 5.84 & 91 & 12 & 31 \\
\hline
\end{tabular}

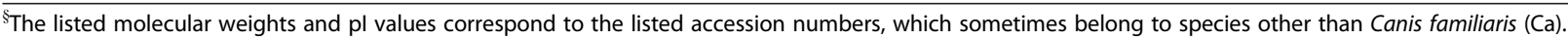
*These proteins were identified by unique peptide sequences determined by MALDI-TOF MS/MS experiments.

Abbreviations: EIF4A: eukaryotic translation initiation factor 4A; TCP-1-alpha: T-complex protein 1, alpha subunit; EIF3: eukaryotic translation initiation factor 3 ACTR2: actin-related protein 2; EIF3: eukaryotic translation initiation factor 3; HSP-ß1: heat shock protein beta-1; PDI: protein disulfide isomerase-associated 3 precursor; CORO-1A: coronin-1A; UPD: Uroporphyrinogen decarboxylase; ANXA6: annexin A6; MCP: Macrophage capping protein; ANXA1: annexin A1; Ca: Canis familiaris; Ho: Homo sapiens; Pan: Pan troglodytes; Ra: Rattus; Go: Gorilla. 
genes had an up-regulated expression, indicating cellular efforts to replace KIT activity and circumvent growth arrest by activation of alternative pro-proliferative pathways. However, as is evident from the long-term follow-up study of masitinib treatment in dogs with non-resectable MCT, development of such alternative pathways are by no means guaranteed [14]. Nonetheless, if present in vivo these pathways may contain potential candidates to be identified as targets for a combined therapy with masitinib to further improve the efficiency of mast cell therapy.

\section{Methods}

\section{Cell line}

C2 cells were kindly provided by Patrice Dubeuil (Institut national de la santé et de la recherche médicale (INSERM), Marseille, France). Cells were cultured in RPMI-1640 with stable glutamine medium (Biowest, Nuaillé, France) supplemented with 10\% FCS (Biowest, Nuaillé, France), sodium pyruvate (Biochrome, Berlin, Germany), MEM non-essential Amino Acids (Biowest, Nuaillé, France) and penicilline/streptomycine (Gibco, Darmstadt, Germany) and kept at $5 \% \mathrm{CO} 2$ and $37^{\circ} \mathrm{C}$. Cells were passaged every 6 to 7 days and rethawed from an original stock every 10 to 12 weeks. In all experiments, cells from passages 3 through 10 were used. On time point 0 cell culture flasks were incubated with $100 \mathrm{nM}$ masitinib Mesylate (AB Science, Paris, France) and kept at 5\% CO2 and $37^{\circ} \mathrm{C}$. Three replicates of RNA and protein were obtained at time point 0 before and after 12, 24, 48 and 72 hours of masitinib incubation. The supernatant of each flask was centrifuged at $500 \mathrm{~g}$ for 5 minutes and washed twice with un-supplemented RPMI-1640 medium (Biowest, Nuaillé, France) with centrifugation steps at 1,000 g for 1 minute. Finally the cell pellet of each flask was equally divided and used for protein or mRNA isolation, respectively. Cell pellets were resolved in $250 \mu$ l protein lysis buffer (GE Healthcare, Freiburg, Germany) or $500 \mu \mathrm{l}$ RA1 lysis buffer (NucleoSpin RNA; Macherey \& Nagel, Düren, Germany) as previously described. Samples were stored at $-80^{\circ} \mathrm{C}$ until further use. Cell numbers were determined at each time point using Trypan Blue exclusion (Biochrome, Berlin, Germany) and viable cells were counted in a Neubauer microscope counting chamber. The experiments with the $\mathrm{C} 2$ cell line were performed according to the European, German and local ethical guidelines of the Freie Universitaet Berlin. Animals, humans and their tissues were not otherwise involved in the study presented here.

\section{WST-1 assay}

For WST and LDH assays, cells were seeded at a density of $1.8 \times 10^{4}$ cells / $\mathrm{ml}$ in 96-well plates (Greiner, Frickenhausen, Germany). Mitochondrial activity was quantified using the Cell Proliferation Reagent WST-1
(Roche Diagnostics GmbH, Mannheim, Germany). Following the indicated treatments of cells, $10 \mu \mathrm{WST}-1$ reagent was added per well (1:10 final dilution). After a 1 hour incubation at $37^{\circ} \mathrm{C}$, the absorbance at $450 / 630 \mathrm{~nm}$ was measured by using an ELISA reader (Bio-Rad Laboratories $\mathrm{GmbH}$, München, Germany).

\section{Lactate dehydrogenase release}

Lactate dehydrogenase (LDH) activity was determined by using the CytoTox-ONETM Homogeneous Membrane Integrity Assay (Promega GmbH, Mannheim, Germany), a fluorimetric method for measuring the release of $\mathrm{LDH}$ from cells with damaged membranes. All reagents were prepared according to the manufacturer's instructions. CytoTox-ONETM reagent $(100 \mu \mathrm{l})$ was added following treatments to each well and incubated for a further 10 minutes. Next, $50 \mu \mathrm{l}$ stop solution was added, the plate was shaken for 10 seconds, and the fluorescent signal was recorded at the 560/590nm excitation/emission wavelength pair by using Fluostar Optima (BMG Labtech $\mathrm{GmbH}$, Offenburg, Germany). Sample triplicates were treated with $5 \mu \mathrm{l}$ lysis solution to perform a $100 \%$ cell lysis control in order to determine the maximum amount of LDH.

\section{Protein and mRNA isolation}

Proteins were extracted in $250 \mu \mathrm{l}$ protein lysis buffer containing $7 \mathrm{M}$ urea, $2 \mathrm{M}$ thiourea, and 4\% CHAPS (3-(3Cholamidopropyl)dimethylammonio-1-propanesulfonate). Lysates were sonicated twice for 2 minutes and then centrifuged at 2,200 g for 2 minutes. The supernatant was collected and stored at $-80^{\circ} \mathrm{C}$ until analysis. Protein concentrations were determined with the 2-D Quant Kit (GE Healthcare, Freiburg, Germany). For mRNA isolation pellets were transferred into $500 \mu \mathrm{l}$ of RA1 lysis buffer (NucleoSpin RNA; Macherey \& Nagel, Düren, Germany) containing $5 \mu \mathrm{l} \beta$-mercaptoethanol and homogenized by pipetting. mRNA was extracted and purified using a commercial system (NucleoSpin RNA; Macherey \& Nagel, Düren, Germany) [22,23].

RNA quality was controlled using the BioAnalyzer (Agilent Technologies, USA) and only high quality RNA $($ RIN $>9)$ was used for microarray analyses.

\section{Microarray data analysis}

Affymetrix GeneChip hybridization (Canine Genome 2.0 Array) was performed with $2 \mu \mathrm{g}$ total RNA according to the manufacturer's recommendations. Three chips for each timepoint of treatment and pretreated cells were stained and washed with the GeneChip Fluidics Station 450 and visualized on an Affymetrix GeneChip Scanner 3000. Microarray data were deposited at the Gene Expression Omnibus data repository under the number GSE32657. 
Affymetrix CEL files were imported into Partek Genomic Suite Software (Version 6.4, Partek Inc., St. Louis, USA) and processed by the implemented gcRMA workflow (median polish probe set summarization, RMA background correction, quantile normalization) [24]. Differences in gene expression between samples at the different time points of masitinib treatment were analysed by ANOVA and false discovery rate was controlled by using the q-value method [25]. Differentially expressed genes were selected by applying a filter of $\mathrm{q}$ $<0.001$ and a fold-change of $>1.5$ in both directions. Un-named genes were excluded from the list. Hierarchical clustering of the samples and genes was conducted using Pearson correlation and complete linkage. Change in expression levels were correlated with the different timpoints and a partial correlation $>0.95$ was accepted as linear correlated.

To supplement the gene annotations of differentially expressed genes with functional information, BLAST search and Affymetrix-provided human to canine microarray comparisons were used to map canine genes to their human equivalents as shown before [26,27]. Using the human equivalents as templates, the DAVID database was queried for gene ontology information [28]. To study enriched functional gene families and functional annotation, all down-regulated and all up-regulated genes were submitted separately to DAVID [29]. In the case of redundant probes with a fold-change in the same direction only the probe set with the highest fold-change was included in further analyses. Selection criteria for DAVID included a medium stringency, $\geq 4$ probes within a cluster and an enrichment factor $>1$.3. In case of multiple appearances of similar gene families or functional annotation terms, the cluster with the higher enrichment factor was selected.

\section{D-DIGE and MALDI-TOF}

Two-dimensional difference gel electrophoresis (2D-DIGE) was used to quantify and compare the proteome in triplicates of C2 cell pellets before and after 24 and 72 hours of masitinib treatment. Protein extracts were labelled with CyDyes (GE Healthcare, Freiburg, Germany) as previously described [30]. The internal standard was composed of equal amounts of all protein lysates used. $50 \mu \mathrm{g}$ of protein of the respective samples were labelled with $400 \mathrm{pmol}$ of the respective dye. Two cell pellet probes and the internal standard were then combined and an equal volume of $2 \times$ sample buffer (7 M urea, $2 \mathrm{M}$ thiourea, 4\% CHAPS, $2 \%$ Pharmalyte IPG Buffer, 2\% DTT, 0.04\% bromophenol blue) was added. Rehydration buffer (7 M urea, $2 \mathrm{M}$ thiourea, $4 \%$ CHAPS, 2\% pharmalyte IPG buffer, 40 mM DTT) was used to yield a final volume of $450 \mu \mathrm{l}$. The Cy-labelled samples were applied to immobilised non-linear $\mathrm{pH}$ gradient (IPG) strips, pH 3-7 (GE Healthcare, Freiburg, Germany), and strips were allowed to rehydrate in the dark at room temperature overnight. Isoelectric focusing (IEF) was performed using an Ettan IPGphor 3 Isoelectric Focusing Unit (Ettan IPGphor Manifold; GE Healthcare, Freiburg, Germany) for a total of $50 \mathrm{kVh}$ at $20^{\circ} \mathrm{C}, 75 \mu \mathrm{A} /$ strip.

Two steps of equilibration followed IEF: 15 minutes with equilibration buffer (6 M urea, 30\% glycerol, 2\% SDS, and $50 \mathrm{mM}$ Tris, $0.02 \%$ bromophenol blue, $\mathrm{pH} 8.8$ ) containing $100 \mathrm{mg}$ DTT, followed by 15 minutes with equilibration buffer containing $250 \mathrm{mg}$ iodoacetamide. Strips were transferred on top of $24 \mathrm{~cm}$ width, $12.5 \%$ SDS-PAGE gels and sealed with $0.5 \%$ low-melting-point agarose. The second-dimension molecular weight separation was carried out using an Ettan DALTsix Electrophoresis Unit (GE Healthcare, Freiburg, Germany). Running parameters used were $60 \mathrm{~mA}$ for 1 hour, $240 \mathrm{~mA}$ for 1 hour and $300 \mathrm{~mA}$ for 5 hours [31].

CyDye-stained protein spots were visualised with a Typhoon 9400 fluorescence scanner (GE Healthcare, Freiburg, Germany) at the respective wavelengths for the three CyDyes. Spot detection, matching and quantification of spot intensity were performed using the DeCyder 2D Software, Version 7.0 (GE Healthcare, Freiburg, Germany). Differences in expression between the different durations of masitinib treatment were analysed using an unpaired student's $t$ test with $p$-values $<0.05$ considered significant. No multiple testing or FDR adjustment was done. Gels with $350 \mu \mathrm{g}$ of protein were silver-stained and spots were picked for subsequent MS analysis [32].

\section{Protein identification by MALDI-TOF-MS}

For protein identification by matrix-assisted laser desorption/ionisation time-of-flight mass spectrometry (MALDI-TOF-MS) an Ultraflex-II TOF/TOF instrument (Bruker Daltonics, Bremen, Germany) equipped with a Smart beam $^{\mathrm{Tm}}$ laser was used. Peptides were obtained by trypsin in-gel digestion as previously described [32]. Protein digests were measured in the reflector mode using $\alpha$-cyano-4-hydroxycinnamic acid (CHCA) as matrix. For the database search, listed contamination peaks from keratin and autoproteolytic products were excluded for peptide mass fingerprint database search with the Mascot server (www.matrixscience.com) in the NCBInr database. The search was restricted to mammalian sequences and one missed tryptic cleavage was considered. A mass accuracy of 50-100 ppm was used for the searches.

\section{Additional files}

Additional file 1: List of genes with significant changes in mRNA expression levels after $12 \mathrm{~h}, 24$ and 72 hours of masitinib treatment.

Additional file 2: Genes with a time-dependent, continuous increase or decrease in mRNA expression level during masitinib treatment. 


\section{Competing interests}

All authors declare to have no financial or non-financial competing interests.

\section{Authors' contribution}

RK conceived, organized, coordinated the study and experiments, and drafted the manuscript. RK, DL, MH carried out the microarray experiments and analyzed the data. AM and RK carried out the cell culture experiments. $A M$ and $A B$ carried out the WST and LDH assays. PS, AB, RE performed the 2D-DIGE experiments. PS and CW carried out the mass spectrometry. ADG helped to conceive the study and to draft the manuscript. All authors read and approved the final manuscript.

\section{Acknowledgements}

We thank Monika Schaerig and Stephanie Mende for excellent technical assistance. We also thank Dr. Tom Chapuis, AB Science for providing masitinib and Patrice Dubeuil (Institut national de la santé et de la recherche médicale (INSERM), Marseille, France) for providing the C2 cells.

\section{Author details}

'Department of Veterinary Pathology, Freie Universität Berlin, Robert-von-Ostertag-Strasse 15, Berlin 14163, Germany. ${ }^{2}$ Department of Veterinary Biochemistry, Berlin, Germany. ${ }^{3}$ Institute of Chemistry/ Biochemistry, Berlin, Germany. ${ }^{4}$ Institute of Pathology, Charité Universitätsmedizin, Berlin, Germany.

Received: 3 January 2012 Accepted: 7 June 2012

Published: 29 June 2012

\section{References}

1. Liao AT, Chien MB, Shenoy N, Mendel DB, McMahon G, Cherrington JM, London CA: Inhibition of constitutively active forms of mutant kit by multitargeted indolinone tyrosine kinase inhibitors. Blood 2002, 100(2):585-593.

2. Taylor F, Gear R, Hoather T, Dobson J: Chlorambucil and prednisolone chemotherapy for dogs with inoperable mast cell tumours: 21 cases. J Small Anim Pract 2009, 50(6):284-289.

3. Mayer MN: Radiation therapy for canine mast cell tumors. Can Vet J 2006, 47(3):263-265.

4. London CA, Hannah AL, Zadovoskaya R, Chien MB, Kollias-Baker C, Rosenberg M, Downing S, Post G, Boucher J, Shenoy N, Mendel DB, McMahon G, Cherrington JM: Phase I dose-escalating study of SU11654, a small molecule receptor tyrosine kinase inhibitor, in dogs with spontaneous malignancies. Clin Cancer Res 2003, 9(7):2755-2768.

5. London CA, Kisseberth WC, Galli SJ, Geissler EN, Helfand SC: Expression of stem cell factor receptor (c-kit) by the malignant mast cells from spontaneous canine mast cell tumours. J Comp Pathol 1996, 115(4):399-414.

6. Letard S, Yang Y, Hanssens K, Palmerini F, Leventhal PS, Guery S, Moussy A, Kinet JP, Hermine O, Dubreuil P: Gain-of-function mutations in the extracellular domain of KIT are common in canine mast cell tumors. Mol Cancer Res 2008, 6(7):1137-1145.

7. Webster JD, Yuzbasiyan-Gurkan V, Miller RA, Kaneene JB, Kiupel M: Cellular proliferation in canine cutaneous mast cell tumors: associations with C-KIT and its role in prognostication. Vet Pathol 2007, 44(3):298-308.

8. Zemke D, Yamini B, Yuzbasiyan-Gurkan V: Mutations in the juxtamembrane domain of C-KIT are associated with higher grade mast cell tumors in dogs. Vet Pathol 2002, 39(5):529-535.

9. Hahn KA, Ogilvie G, Rusk T, Devauchelle P, Leblanc A, Legendre A, Powers B, Leventhal PS, Kinet JP, Palmerini F, Dubreuil P, Moussy A, Hermine O: Masitinib is safe and effective for the treatment of canine mast cell tumors. J Vet Intern Med 2008, 22(6):1301-1309.

10. Gleixner KV, Rebuzzi L, Mayerhofer M, Gruze A, Hadzijusufovic E, Sonneck K, Vales A, Kneidinger M, Samorapoompichit P, Thaiwong T, Pickl WF, Yuzbasiyan-Gurkan V, Sillaber C, Willmann M, Valent P: Synergistic antiproliferative effects of KIT tyrosine kinase inhibitors on neoplastic canine mast cells. Exp Hematol 2007, 35(10):1510-1521.

11. Isotani M, Ishida N, Tominaga M, Tamura K, Yagihara H, Ochi S, Kato R, Kobayashi T, Fujita M, Fujino Y, Setoguchi A, Ono K, Washizu T, Bonkobara $\mathrm{M}$ : Effect of tyrosine kinase inhibition by imatinib mesylate on mast cell tumors in dogs. J Vet Intern Med 2008, 22(4):985-988.
12. London CA, Malpas PB, Wood-Follis SL, Boucher JF, Rusk AW, Rosenberg MP, Henry CJ, Mitchener KL, Klein MK, Hintermeister JG, Bergman PJ, Couto GC, Mauldin GN, Michels GM: Multi-center, placebo-controlled, doubleblind, randomized study of oral toceranib phosphate (SU11654), a receptor tyrosine kinase inhibitor, for the treatment of dogs with recurrent (either local or distant) mast cell tumor following surgical excision. Clin Cancer Res 2009, 15(11):3856-3865.

13. Dubreuil $P$, Letard S, Ciufolini M, Gros L, Humbert M, Casteran N, Borge L, Hajem B, Lermet A, Sippl W, Voisset E, Arock M, Auclair C, Leventhal PS, Mansfield CD, Moussy A, Hermine O: Masitinib (AB1010), a potent and selective tyrosine kinase inhibitor targeting KIT. PLoS One 2009, 4(9):e7258.

14. Hahn KA, Legendre AM, Shaw NG, Phillips B, Ogilvie GK, Prescott DM, Atwater SW, Carreras JK, Lana SE, Ladue T, Rusk A, Kinet JP, Dubreuil P, Moussy A, Hermine O: Evaluation of 12- and 24-month survival rates after treatment with masitinib in dogs with nonresectable mast cell tumors. Am J Vet Res 2010, 71(11):1354-1361.

15. Thamm DH, Rose B, Kow K, Humbert M, Mansfield CD, Moussy A, Hermine O, Dubreuil P: Masitinib as a chemosensitizer of canine tumor cell lines: A proof of concept study. Vet J 2011, 191(1):131-134.

16. Humbert M, Casteran N, Letard S, Hanssens K, lovanna J, Finetti P, Bertucci F, Bader T, Mansfield CD, Moussy A, Hermine O, Dubreuil P: Masitinib combined with standard gemcitabine chemotherapy: in vitro and in vivo studies in human pancreatic tumour cell lines and ectopic mouse model. PLoS One 2010, 5(3):e9430.

17. Mitry E, Hammel P, Deplanque G, Mornex F, Levy P, Seitz JF, Moussy A, Kinet JP, Hermine $O$, Rougier $P$, Raymond E: Safety and activity of masitinib in combination with gemcitabine in patients with advanced pancreatic cancer. Cancer Chemother Pharmacol 2010, 66(2):395-403.

18. Lindblad-Toh K, Wade CM, Mikkelsen TS, Karlsson EK, Jaffe DB, Kamal M, Clamp M, Chang JL, Kulbokas EJ 3rd, Zody MC, Mauceli E, Xie X, Breen M, Wayne RK, Ostrander EA, Ponting CP, Galibert F, Smith DR, DeJong PJ, Kirkness E, Alvarez P, Biagi T, Brockman W, Butler J, Chin CW, Cook A, Cuff J, Daly MJ, DeCaprio D, Gnerre S, Grabherr M, Kellis M, Kleber M, Bardeleben C, Goodstadt L, Heger A, Hitte C, Kim L, Koepfli KP, Parker HG, Pollinger JP, Searle SM, Sutter NB, Thomas R, Webber C, Baldwin J, Abebe A, Abouelleil A, Aftuck L, Ait-Zahra M, Aldredge T, Allen N, An P, Anderson S, Antoine C, Arachchi H, Aslam A, Ayotte L, Bachantsang P, Barry A, Bayul T, Benamara M, Berlin A, Bessette D, Blitshteyn B, Bloom T, Blye J, Boguslavskiy L, Bonnet C, Boukhgalter B, Brown A, Cahill P, Calixte N, Camarata J, Cheshatsang Y, Chu J, Citroen M, Collymore A, Cooke P, Dawoe T, Daza R, Decktor K, DeGray S, Dhargay N, Dooley K, Dorje P, Dorjee K, Dorris L, Duffey N, Dupes A, Egbiremolen O, Elong R, Falk J, Farina A, Faro S, Ferguson D, Ferreira P, Fisher S, FitzGerald M, Foley K, Foley C, Franke A, Friedrich D, Gage D, Garber M, Gearin G, Giannoukos G, Goode T, Goyette A, Graham J, Grandbois E, Gyaltsen K, Hafez N, Hagopian D, Hagos B, Hall J, Healy C, Hegarty R, Honan T, Horn A, Houde N, Hughes L, Hunnicutt L, Husby M, Jester B, Jones C, Kamat A, Kanga B, Kells C, Khazanovich D, Kieu AC, Kisner P, Kumar M, Lance K, Landers T, Lara M, Lee W, Leger JP, Lennon N, Leuper L, LeVine S, Liu J, Liu X, Lokyitsang Y, Lokyitsang T, Lui A, Macdonald J, Major J, Marabella R, Maru K, Matthews C, McDonough S, Mehta T, Meldrim J, Melnikov A, Meneus L, Mihalev A, Mihova T, Miller K, Mittelman R, Mlenga V, Mulrain L, Munson G, Navidi A, Naylor J, Nguyen T, Nguyen N, Nguyen C, Nicol R, Norbu N, Norbu C, Novod N, Nyima T, Olandt P, O'Neill B, O'Neill K, Osman S, Oyono L, Patti C, Perrin D, Phunkhang P, Pierre F, Priest M, Rachupka A, Raghuraman S, Rameau R, Ray V, Raymond C, Rege F, Rise C, Rogers J, Rogov P, Sahalie J, Settipalli S, Sharpe T, Shea T, Sheehan M, Sherpa N, Shi J, Shih D, Sloan J, Smith C, Sparrow T, Stalker J, StangeThomann N, Stavropoulos S, Stone C, Stone S, Sykes S, Tchuinga P, Tenzing $P$, Tesfaye S, Thoulutsang D, Thoulutsang Y, Topham K, Topping I, Tsamla T, Vassiliev $H$, Venkataraman $V$, Vo A, Wangchuk T, Wangdi T, Weiand M, Wilkinson J, Wilson A, Yadav S, Yang S, Yang X, Young G, Yu Q, Zainoun J, Zembek L, Zimmer A, Lander ES: Genome sequence, comparative analysis and haplotype structure of the domestic dog. Nature 2005, 438(7069):803-819.

19. Osborne CS, Chakalova L, Brown KE, Carter D, Horton A, Debrand E, Goyenechea B, Mitchell JA, Lopes S, Reik W, Fraser P: Active genes dynamically colocalize to shared sites of ongoing transcription. Nat Genet 2004, 36(10):1065-1071.

20. Fournier ML, Paulson A, Pavelka N, Mosley AL, Gaudenz K, Bradford WD, Glynn E, Li H, Sardiu ME, Fleharty B, Seidel C, Florens L, Washburn MP: 
Delayed correlation of mRNA and protein expression in rapamycintreated cells and a role for Ggc1 in cellular sensitivity to rapamycin. $\mathrm{Mol}$ Cell Proteomics 2010, 9(2):271-284.

21. Hack CJ: Integrated transcriptome and proteome data: the challenges ahead. Brief Funct Genomic Proteomic 2004, 3(3):212-219.

22. Klopfleisch R, Gruber AD: Derlin-1 and stanniocalcin-1 are differentially regulated in metastasizing canine mammary adenocarcinomas. J Comp Pathol 2009, 141(2-3):113-120

23. Klopfleisch R, Klose P, Gruber AD: The combined expression pattern of BMP2, LTBP4, and DERL1 discriminates malignant from benign canine mammary tumors. Vet Pathol 2010, 47(3):446-454.

24. Wu Z, Irizarry RA: Preprocessing of oligonucleotide array data. Nat Biotechnol 2004, 22(6):656-658. author reply 658.

25. Benjamini $Y$, Hochberg $Y$ : Controlling the false discovery rate - a practical and powerful approach to multiple testing. J Roy Stat Soc B Met 1995, 57(1):289-300.

26. Cardin S, Libby E, Pelletier P, Le Bouter S, Shiroshita-Takeshita A, Le Meur N, Leger J, Demolombe S, Ponton A, Glass L, Nattel S: Contrasting gene expression profiles in two canine models of atrial fibrillation. Circ Res 2007, 100(3):425-433.

27. Klopfleisch R, Lenze D, Hummel M, Gruber AD: Metastatic canine mammary carcinomas can be identified by a gene expression profile that partly overlaps with human breast cancer profiles. BMC Cancer 2010, 10:618.

28. da Huang W, Sherman BT, Lempicki RA: Systematic and integrative analysis of large gene lists using DAVID bioinformatics resources. Nat Protoc 2009, 4(1):44-57.

29. Klopfleisch R, Lenze D, Hummel M, Gruber AD: The metastatic cascade is reflected in the transcriptome of metastatic canine mammary carcinomas. Vet J 2010, 190(2):236-243.

30. Klopfleisch R, Klose P, Weise C, Bondzio A, Multhaup G, Einspanier R, Gruber AD: Proteome of metastatic canine mammary carcinomas: similarities to and differences from human breast cancer. J Proteome Res 2010, 9(12):6380-6391.

31. Klose P, Weise C, Bondzio A, Multhaup G, Einspanier R, Gruber AD, Klopfleisch R: Is there a malignant progression associated with a linear change in protein expression levels from normal canine mammary gland to metastatic mammary tumors? J Proteome Res 2011, 10(10):4405-4415.

32. Shevchenko A, Wilm M, Vorm O, Mann M: Mass spectrometric sequencing of proteins silver-stained polyacrylamide gels. Anal Chem 1996, 68(5):850-858

doi:10.1186/1746-6148-8-96

Cite this article as: Klopfleisch et al:: Transcriptome and proteome analysis of

tyrosine kinase inhibitor treated canine

mast cell tumour cells identifies potentially

kit signaling-dependent genes. BMC Veterinary Research 2012 8:96.

\section{Submit your next manuscript to BioMed Central and take full advantage of:}

- Convenient online submission

- Thorough peer review

- No space constraints or color figure charges

- Immediate publication on acceptance

- Inclusion in PubMed, CAS, Scopus and Google Scholar

- Research which is freely available for redistribution 